\title{
FORMAÇÃO DE PROFESSORES DO ENSINO PRIMÁRIO NO CONTEXTO DA DIVERSIDADE CULTURAL - UM OLHAR AOS PROFESSORES DE LÍNGUA PORTUGUESA EM MOÇAMBIQUE ${ }^{1}$
}

Félix Alexandre Nhambe ${ }^{2}$

\begin{abstract}
Resumo: Com este artigo, pretendemos abordar a formação de professores primários de língua portuguesa no contexto da diversidade cultural, com a finalidade de reflectir sobre o currículo de formação de professores primários em Moçambique. A metodologia usada consistiu na pesquisa bibliográfica e documental na base do Plano Curricular do Curso de Formação de Professores do Ensino Primário e Educadores de Adultos entre outros documentos e as falas de 14 professores entrevistados. Parece-nos que há a necessidade de incorporação da Pedagogia da Diversidade e Desenvolvimento Curricular na formação de professores, pois elas não estão previstas e cursos solidificados, seguros e estáveis de professores. Estas preparariam aos futuros professores em reflexão crítica do currículo do Ensino Básico e em desenvolvimento da consciência nos alunos sobre a diversidade linguística, cultural e da biodiversidade, no sentido de orientá-los para uma actividade que lhes é significativa, possibilitando-os na construção da sua identidade, da condição humana e da cidadania no quadro da teoria pós-estruturalista e pós-crítica. Ter um professor bilingue equilibrado seria um cenário adequado tendo em conta o local de trabalho e uma política linguística que favorece todas as línguas
\end{abstract} do espaço moçambicano no ensino. Sem estas ferramentas pode haver dificuldades para os professores porque estes vão trabalhar num contexto de diversidade cultural e linguística, devendo leccionar, por vezes, as línguas Bantu e o Português, não bastando o conhecimento das Estruturas das Línguas Bantu, da Didáctica da Língua Primeira/Materna, Didáctica da Língua Segunda, Língua Portuguesa, Literatura Oral, da situação linguística e cultural do país.

Palavras-chave: Currículo; Formação de Professores; Didáctica da Diversidade; Diversidade cultural

\section{Introdução}

A formação de professores primários no nosso país ainda constitui um desafio, partindo do pressuposto que o sucesso das crianças moçambicanas advém de professores qualificados. No nosso contexto multilingue e de diversidade cultural, estes professores trabalham em espaços em que se coabitam várias línguas e culturas

\footnotetext{
${ }^{1}$ Artigo escrito no português de Moçambique.

${ }^{2}$ Doutorando em Educação/Currículo, Mestre em Educação, Licenciado em Ensino do Português. Professor na Universidade Rovuma.Email: fnhambe32@gmail.com
} 
e as questões centrais são - o que fazer no currículo de formação dos professores primários? Que didácticas a privilegiar para a formação de futuros professores? Que línguas deviam ser usadas como meio de ensino? Como ensinar a escrever e a ler a uma criança monolingue, bilingue e poliglota? A língua portuguesa, sendo oficial e factor de visibilidade a nível nacional e internacional, é igualmente as mais de 20 línguas Bantu (LB), faladas entre Zumbo ao Oceano Índico e Maputo ao Rio Rovuma, constituem como línguas identidade nacional moçambicana.

Moçambique, na procura de ajustar e garantir uma formação de professores do Ensino Primário em função do contexto actual, introduziu, em 2019, o Plano Curricular do Curso de Formação de Professores do Ensino Primário e Educadores de Adultos, mas em alguns (Institutos de Formação de Professores (IFPs) até hoje há ainda cursos do plano curricular de $10^{\mathrm{a}}+1$ Ano e $10^{\mathrm{a}}+3 \mathrm{Anos}^{3}$ e, quando as condições tiverem criadas, introduzirão este novo plano curricular de formação de professores primários. Esta intodução procura "fortalecer a formação, valorização e motivação dos professores no sistema da educação (...) [e responder] aos desafios de promoção de um ensino de qualidade e inclusivo, através de abordagens de ensino integradoras e centradas no aluno" (INDE \& MINEDH ${ }^{4}, 2019$, p. 6).

Os professores de língua portuguesa têm dificuldades diversas no processo de ensino e aprendizagem e para exemplificar é o caso, primeiramente, dos professores não saberem lidar na sala de aula com crianças que falam diferentes línguas; em segundo lugar, escassez e/ou ausência de dicionários, gramáticas e prontuários das línguas bantu (e material didáctico diverso em Português para os alunos); em terceiro lugar, défice epistemológico da Didáctica de Língua Materna e Didáctica da Língua Segunda; e em quarto lugar as turmas que se considera por numerosa.

É neste rumo, que no presente artigo, pretendemos reflectir sobre a formação de professores de língua portuguesa do enisino primário no contexto da diversidade cultural em Moçambique.

A metodologia usada consistiu na pesquisa bibliográfica, tomando como base o Plano Curricular do Curso de Formação de Professores do Ensino Primário e Educadores de Adultos, e aplicou-se a entrevista que foi submetida a 14 professores no âmbito da recolha do corpus para a escrita da tese com o título "A construção da identidade profissional: um estudo centrado nos professores de Língua Portuguesa do III Ciclo do Ensino Primário".

Este artigo é composto por três partes, quais sejam, a reflexão sobre o currículo de formação de professores, primeiro, a Pedagogia da Diversidade e a construção da identidade do professor da Língua Portuguesa na diversidade, terceira.

\footnotetext{
${ }^{3}$ O Curso de $10^{\mathrm{a}}+1$ Ano é de duração de um ano e de $10^{\mathrm{a}}+3$ Anos tem a duração de 3 anos. Em ambos os cursos, ingressa formandos com $10^{\mathrm{a}}$ classe.

${ }^{4}$ INDE - Instituto Nacional de Desenvolvimento da Educaçao; MINEDH - Ministério da Educação e Desenvolvimento Humano.
} 


\section{0 currículo de formação de professores}

Procuraremos fazer reflexão das teorias de currículos e a trajectória para a formação de professores na base do currículo escolar e a sua gestão.

O currículo é uma cultura individual e de um grupo. Por quê e como? As experiências mostram-nos que a priori quando o aluno entra na escola se sujeita a determinado currículo escolar. Este aluno vai vivenciando as experiências e as práticas pedagógico-didácticas de vários professores durante a trajectória estudantil, construindo referências. São as referências dos professores e as intervenções do aluno em aulas, nos seminários, nas apresentações de actividades na escola entre outras acções que vão estimular a continuação deste a enveredar pela formação de professores ${ }^{5}$.

Durante o percurso na formação de professores, o aluno-formando vai se familiarizar com um novo paradigma que é a noção do currículo escolar e o entendimento do currículo no qual vai trabalhar e da profissão docente, isto é, sai da socialização meramente de aluno para o professorado que resultou das referências dos seus professores nas classes anteriores, ou seja, factores que contribuem para a evocação a docência.

Quando professor também vivencia as experiências dos outros professores, dos alunos e da comunidade na qual está inserida a escola, ele também vai decidir na tomada do rumo ou mudança na sua prática docente porque a cultura da comunidade e escolar vai contribuir para humanizá-lo. A complexidade da profissão de professor obriga-nos a compreender melhor o campo educacional e as especificidades das nossas culturas e comunidades específicas. Isto permite o enquadramento da construção dum currículo e é nesta perspectiva e trajectória que se constrói o currículo individual ou de grupo.

Assim, as teorias, os modelos e a avaliação curricular são pressupostos para a construção do currículo e das práticas educativas dos professores no contexto da diversidade, do multiculturalismo e do multilinguismo e do currículo de formação de professores.

O currículo de formação de professores é uma diversificação e complexidade de actividades alargadas, campo de definição dos programas de ensino, de formação de professores e identidade, de dotação da arte de ensinar e aprender, englobando as prévias experiências e socialização dos docentes a partir da sua passagem pela escola como alunos, vivências na formação e no local de trabalho - a escola. Também, um campo ou espaço de luta, de saber, dos objectivos de um sistema educativo para a formação de uma sociedade com um determinado perfil ou identidade, é um conflito social, um programa de trabalho, conteúdo apresentado para

\footnotetext{
5 “É a área de conhecimentos, investigação e de propostas teóricas e práticas que, no âmbito da Didáctica e da Organização Escolar, estuda os processos através dos quais os professores - em formação ou em exercício - se implicam individualmente ou em equipa, em experiências de aprendizagem através das quais adquirem ou melhoram os seus conhecimentos, competências e disposições, e que lhes permitem inferir profissionalmente no desenvolvimento do seu ensino, do currículo e da escola, com objectivo de melhorar a qualidade da educação que os alunos recebem" (GARCÍA, 1999, p. 26).
} 
estudo, construído, produzido, negociado e reproduzido socialmente, organização de um sistema educacional ou de formação ou sequência estruturada de disciplinas, estabelecendo uma ordem social (GOODSON, 2003); é um texto, prática de significação e é formal, vivido e oculto (LOPES; MACEDO, 2011). O conceito de currículo é complexo e deve ser entendido como uma (des)construção política, social, cultural e ideológica das práticas dos sistemas educativos, organizadas ao nível formal, presencial e oculto/informal, e visto em duas visões: sentido alargado (amplo ou lato) e sentido restrito.

Admais, o currículo, mesmo sendo complexo, deve ser aquele que traduz as experiências, práticas, preocupações e questionamentos do homem, resultante também do repensar dos currículos anteriores e presentes, com uma perspectiva visionária e crítica da acção educativa, isso quer dizer, este artefacto social, deve ser, segundo Nhalivilo (2017), um currículo sábio que resulta das perguntas fortes e da inter/pluridiversidade - construir um jardim com muitas flores e não com uma única flor. Sendo assim, o currículo de formação de professores não deve ser entendido como um programa de actividades escolar e de formação, um texto, um plano, etc., mas como sendo todas as acções que assentam e interferem no processo de ensino-aperendizagem (PEA) e formação dentro e fora da instituição educativa numa perspectiva formal ou informal.

O currículo, sendo um campo de estudo e de interesses, um artefacto social, político, ideológico e cultural que visa a transformação de pessoas através de conhecimentos, uma formação, um ensino, uma instrução e educação com dualidade de crenças e saber num percurso ou trajectória individual ou colectiva, assenta na formação do(s) indivíduo(s) através de objectivos, duma prática pedagógica e gestão do mesmo. Este representa

um processo que admite uma lógica de desconstrução, com a introdução de sucessivos discursos cujo significado se apreende pela hermenêutica e da prática, e optar por uma abordagem processual que faz a inter-relação das duas componentes intrínsecas presentes em qualquer projecto curricular: o que se pretende (expectativas e intenções curriculares) bem como o quê e onde ocorre (realidade curricular). (...) O currículo é, cumulativamente, uma intenção e uma realidade que ocorre num contexto determinado, e que são o resultado de decisões tomadas em vários contextos (PACHECO, 2000, p. 7).

Ainda, este requer uma gestão que assenta na descentralização, democratização, transferência de poderes para outras unidades orgânicas, tomada de decisão partilhada e acções colaboradas, adaptação, liderança, responsabilização e participação activa dos actores da escola, eficácia da escola, proporcionando o desenvolvimento da qualidade de ensino. Mas a gestão do currículo não é só tarefa do professor e gestor, além destes, outros actores também participam, nomeadamente: pais e encarregados da educação, alunos, a comunidade e entidades institucionais que 
zelam pela educação de modo a se garantir o sucesso das intenções da política educacional e curricular do Governo.

E a gestão do currículo passa pelo desenvolvimento curricular e vice-versa, isto é, na planificação, organização, direcção e liderança (supervisão), deve, simultaneamente, ocorrer o desenvolvimento curricular e a gestão, pois a gestão está para o desenvolvimento curricular havendo o equilíbrio, sendo mais gestão e mais desenvolvimento curricular e não mais gestão/desenvolvimento curricular e menos desenvolvimento curricular/gestão porque sem equilíbrio de mais gestão curricular e desenvolvimento curricular se verifica má gestão, como ilustra a figura 1.

Figura 1: Esquema de gestão curricular e desenvolvimento curricular

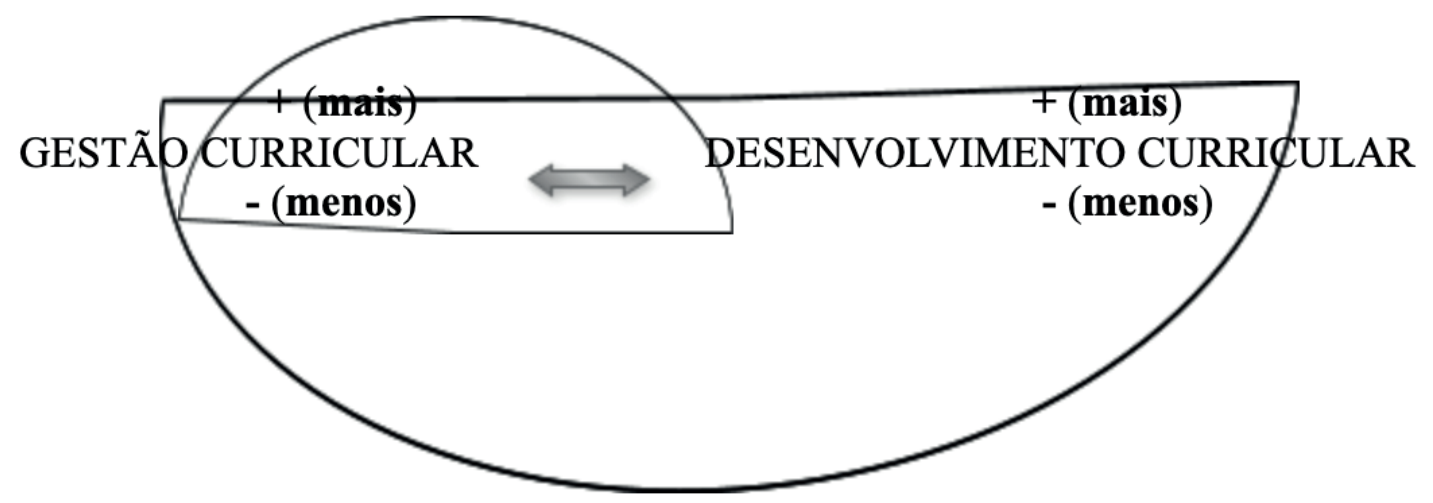

Os processos de gestão são procedidos sobre o currículo oficial que é apresentado a todos, em especial ao professor que é o gestor central do currículo, e em contexto da acção - a unidade educacional que é uma escola ou instituição educacional. $\mathrm{O}$ currículo educacional, sendo institucional, um instrumento técnico e específico, um espaço de acção pública (do Estado), irá dar dois níveis, a saber: o sistema educacional: em vários subsistemas - ensino primário, ensino secundário, ensino técnico-profissional e ensino superior e a unidade educacional: centros infantis, escolas, institutos, academias e universidades, devendo o currículo ser gerido.

Hoje se discute bastante o papel do currículo educacional pelos curriculistas ou estudiosos de currículo, bem como os políticos, os professores, os gestores, a comunidade em geral, as organizações nacionais e internacionais ou as Organizações Não Governamentais (ONGs), também fazem reflexões sobre as questões curriculares. E actualmente as reflexões curriculares e de formação de professores, no caso da língua portuguesa, têm enquadramento epistemológico e metodológico no paradigma pós-estruturalista e teorias pós-críticas.

Com as críticas e o reconhecimento da primazia da pedagogia, emerge a necessidade se criar programas curriculares apropriados aos profissionais da educação com os argumentos das instituições e currículos de formação de professores cujos futuros professores, como quadros intelectuais, possam de forma democrática, libertada, emancipada e crítica reflectir e legitimar os discursos curriculares, já que o trabalho docente, está actualmente, em interrogações extremas. 
E a prática crítica pode ser também o "papel mais activo dos professores [que] tem reflexão muito profunda na estrutura curricular"(PACHECO, 2001, p. 42). Para este autor, o professor propõe e adopta uma acção estratégica de ensino, criticando a sua praxis.Esta capacidade crítica do professor está no poder científico que tem e a reflexão sobre as suas práticas pedagógicas favorece a reconstrução da identidade sua, da escola e da sociedade, desenvolvendo práticas curriculares que alavancam o sucesso da educação.

Estando, actualmente, no mundo global, multicultural, da diversidade e com a hegemonia do neoliberalismo, os currículos são, na maioria deles, desenhados na base da teoria de matriz fenomenológica (LOPES; MACEDO, 2011) ou das teorias pós-críticas (TADEU DA SILVA, 2017a, Cortesão; STOER, 2003, POURTOIS; DESMET, 1999, PINAR, 1994) e no paradigma pós-estruturalista do currículo (TADEU DA SILVA, 2017a, PACHECO, 2001, 2005). As teorias pós-críticas e o pós-estruturalismo do currículo, assentes na pós-modernidade e na contemporaneidade, orientam-se por várias categorias, a saber: a identidade cultural particular e a cultura nacional, o hibridismo e a diáspora (HALL, 2011), a diferença e a identidade, a raça e a etnia, o género (feminismo), (TADEU DA SILVA, 2017a, HALL, 2011), a reestruturação e a educação intercultural, o discurso e a recontextualização pedagógica (conteúdos, saberes e significados), a gestão da diversidade, (CORTESÃO; STOER, 2003, PINER, 1994, 2004), a racionalização, a subjectivacão, a integração, (POURTOIS; DESMET, 1999), o capital linguístico, a reprodução e a representação (BOURDIEU; PASSERON, 1992), o discurso e o poder (FOUCAULT, 2014), cultura, multiculturalismo (MCLAREN, 2000), língua (códigos linguísticos) e educação (BERNSTEIN, 1996), políticas curriculares (GOODSON, 2008).

Ao valorizar as dimensões culturais, ou seja, a diversidade cultural no desenvolvimento curricular, está-se alcançar a satisfação do homem no sentido de ver os seus valores respeitados e representados no currículo, não só, ao privilegiar as identidades das pessoas e suas diferenças, também estaremos a resolver problemas práticos que têm a ver com questões de língua, do género, da sexualidade, das diferenças étnicas e da raça entre outros. Traz-se a tona a preocupação dos “excluídos”, por um lado, e por outro, a identidade cultural é privilegiada porque aos grupos minoritários dá-se espaço para que possam expor a sua identidade, pois na contemporaneidade há a emancipação cultural em que se defende a inclusão e o respeito pela diversidade cultural e linguística, como realça Santomé (2013, p. 183) ao apontar duas orientações do compromisso ou da missão da escola, a saber: a) a educação das crianças para conviverem em sociedades multiculturais e multilinguísticas no mundo globalizado e a formação de cidadãos cosmopolitas; b) capacitar as novas gerações para se incorporarem de forma activa e eficaz aos mercados de produção actual.

Na perspectiva de teorias pós-críticas ou de matriz fenomenológica, no currículo ressalta um pensamento crítico, movido pelo modo de vida dos indivíduos e é uma conversa pelas experiências dos sujeitos (LOPES; MACEDO, 2011), a necessidade 
de se valorizar as questões do género, sexualidade e a identidade dos sujeitos no currículo (PINAR, 1994), pois há comprometimento dos alunos quando vêem as suas crenças incluídas no currículo escolar ou de formação. Esta matriz é optimismo crítico (CORTELLA, 2003) porque a educação tem a função conservadora e inovadora, por um lado e por outro lado, reproduz as injustiças e é um campo de inovação a partir das contradições sociais e instrumento de mudança.

Na educação do professor e com os programas curriculares de formação destes que se apresentavam aos formandos, as dificuldades de estimular o papel intelectual para um trabalho duma visão emancipatória, passou-se para a redefinição da especialização, da natureza do trabalho docente e da função social do ensino (GIROUX; MCLAREN, 1999). De igual modo, normalmente, evidencia-se nos currículos de formação de professores uma linguagem crítica, auto-reflexão e a articulação da teoria e da prática em que as visões críticas e reflexivas são revestidas pela união da teoria e prática do conhecimento, luta pela democracia, contra-hegemonia (resistência) e justiça social (ibidem). Hoje há especialização em línguas clássicas, língua de sinais, em formação bivalente (saída com competência em ensinar duas línguas) ou formação bilingue e formação em línguas estrangeiras e/ou locais.

O currículo é uma intenção e uma realidade dum contexto específico, decidido em vários contextos (PACHECO, 2000), por um lado e por outro, sendo dinâmico e processual em todo o seu processo de desenvolvimento, é realmente "uma intersecção de práticas com finalidade de responder a situações concretas” (ibidem: 8), ou seja, os anseios ou interesses e problemas das sociedades. Daí que a reforma de um currículo requer um processo de avaliação, o que dizer que foi feito a avaliação do currículos dos cursos de formação de professores do ensino primário $-10^{\mathrm{a}}+$ 1 Ano e $10^{\mathrm{a}}+3$ Anos para se introduzir o novo Plano Curricular - Curso de Formação de Professores do Ensino Primário e Educadores de Adultos - 2019.

Contudo, espera-se que neste novo currículo moçambicano, se tenha tido em conta os fundamentos de formação de professores, a saber: de ordem filosófica, de ordem psicológica, de ordem sociológica, de ordem antropológica, de ordem histórica, de ordem político-económica, de ordem científico-técnica (CARVALHO, 2002; MOREIRA, 2007), de ordem epistemológica, da complexidade dos fenómenos educativos, de ordem socioprofissional, de ordem ético-profissional.

Os fundamentos de formação de professores também se revestem pelos discursos dos modelos de formação inicial de professores: Modelo Tradicional, Modelo Técnico, Modelo Prático-reflexivo, Modelo Cognitivo e Experimental, Modelo Personalizado e Humanístico, Modelo Crítico (MOREIRA, 2007). Aqui não se pretende discutir a caracterização de cada modelo pois todos se complementam pese embora se considera a epistemologia da prática no processo de formação de professores como a mais válida através do processo de uma formação assente nos modelos críticos e reflexivos que irão atender a diversidade e aos desafios da educação na contemporaneidade e no Séc. XXI, em que "os processos de formação 
estão proporcionando aos professores o grau de domínio dos conhecimentos específicos de seu curso" (BARZOTTO; PUH, 2015, p. 93). Mas as "estratégias pedagógicas como o uso de diário, portfolios, biografias, orientação de estágio são também parte de projectos que visam à formação do professor reflexivo" (LOPES; MACEDO, 2011, p. 154).

Neste processo de formação crítica e reflexiva, os professores desenvolvem os saberes de reflexão-na-acção, da reflexão-sobre-a-acção e sobre-a-reflexão-na-acção (SCHÖN, 1995). Para este autor, o conhecimento-na-acção consiste num saber técnico, isto é, habilidades de saber fazer; a reflexão-na-acção assenta em reconsiderar as confusões do próprio professor e do aluno, aprendendo com os erros (próprios e dos outros) na sua prática e privilegiar o diálogo e a interacção para superar as dificuldades e limitações; e a reflexão-sobre-a-acção reside na realização depois da acção educacional, ou seja, actividade constante de reflexão sobre a prática educativa realizada. Estas três perspectivas reflexivas complementam-se na prática de ensino e no papel do professor, pois assentam numa prática reflexiva. Esta prática reflexiva também é para o formador/professor e os formandos/alunos, em que com a Pedagogia da ou na Diversidade, estes devem aprender sobre as diferenças linguísticas, raciais, familiares, religiosas e entre atitudes e habilidades, aprender com as diferenças culturais e nas diferenças de género (SANTOS, 2005), pois facilitam a interactividade de todos actores da escola.

Esta formação crítica e reflexiva, ao nosso ver, deve ser com um conhecimento mínimo sobre o currículo escolar, ou melhor, o futuro professor deve ter noções sobre teorias curriculares, com isto pretendemos a introdução preliminar de noções de estudos curriculares, como é o caso da disciplina de Desenvolvimento Curricular.

\section{Pedagogia da e na Diversidade}

O novo Plano Curricular do Curso de Formação de Professores do Ensino Primário e Educadores de Adultos moçambicano, sendo rico em vários aspectos, $\mathrm{e}$ sem a Pedagogia da Diversidade (SANTOS, 2005) ou Didáctica da Diversidade (DIAS, 2009) e Desenvolvimento Curricular, poderá colocar dificuldades aos professores de Língua Portuguesa (PLP) porque os futuros professores vão trabalhar num contexto da diversidade cultural e linguística e que devem leccionar, em algumas classes, as línguas Bantu (LB) e o Português, não bastando, somente, o conhecimento das disciplinas de Estruturas das Línguas Bantu (Moçambicanas), Língua de Sinais de Moçambique, Didáctica da Língua Primeira (Materna) e Didáctica da Língua Segunda, Língua Portuguesa (I e II), Literatura Oral em Línguas Moçambicanas, Literatura Infanto-Juvenil em Língua Portuguesa.

Entendemos aqui que incorporar estas duas disciplinas prepararia os futuros professores em reflexão crítica do currículo do Ensino básico e em desenvolvimento da consciência nos alunos sobre a diversidade linguística, cultural e da biodiversidade, no sentido de orientar o aluno para uma actividade que lhe é significativa, 
sendo que a escola não pode ser vista como um espaço uniformizador, mas sim, espaço que possibilita a construção da identidade, da condição humana e da cidadania. Perceberiam os formandos e/ou os professores em como lidar com as LB e como ensiná-las, sabendo nós que apresentam estrutura diferente do Português. Difícil é leccionar a Língua Segunda num contexto do pluralismo linguístico porque cada língua nos apresenta diferentes estratégias de compreensão e representação do nosso universo. Importa referir que DIAS (2009) já fez menção da Didáctica da Diversidade ser incorporada no currículo de formação de professores, dando até as propostas dos conteúdos a serem leccionados.

O professor de Português, já trabalhando num contexto multilingue, hoje tem sofrido algumas influências das línguas Bantu e pela presença de comunidades linguísticas diversas, vindo dos países da Ásia, África Oriental, Central e do Norte e Europa contribuem para o aumento e enriquecimento do nosso mosaico linguístico, cultural e diversidade. Neste contexto a Pedagogia da Diversidade é fundamental e esta é a acção pedagógica-didáctica que o professor aplica para "ajudar a clarear a importância de valores, como a tolerância, a solidariedade, a igualdade, o respeito ao outro, a cooperação e o profundo valor do diálogo como método de reconhecimento do novo por meio de nossas experiências de vida e da cultura de nossos povos" (SANTOS, 2005, p. 30).

Notamos que a situação multilingue no país é extremamente complexa e um processo de ensino e aprendizagem (PEA) eficaz tem como base central a mediação por línguas que tanto o aluno e o professor dominem perfeitamente, daí o factor para o sucesso escolar, mas é uma missão difícil aos professores. Também a prática da Didáctica da Diversidade, consequentemente, permite aos professores "que consigam fazer com que cada aluno seja reorientado para uma actividade significativa para ele, necessitando que o professor compreenda o que se passa no mundo subjectivo dos alunos, para que se instale o diálogo entre o saber e a aprendizagem" (ibidem, p. 36). E ainda para esta autora, a pedagogia na diversidade deve ser aquela que $\mathrm{E}$ ainda para esta autora, a pedagogia na diversidade deve ser aquela que busque reestruturação organizacional e reelaboração de currículos das escolas, reavaliação das expectativas dos professores e funcionários em relação aos estudantes, no sentido dos alunos oriundos de diferentes grupos éticos e sociais participem com igualdade de condições das experiências educativas, praticando pedagogias que têm por base os princípios da equidade, cujo ensino garante o sucesso de todos alunos, independentemente da classe social, do grupo étnico, social e linguístico a que pertencem (op.cit).

Neste novo plano curricular de formação de professores do Ensino Primário, os formandos já munidos de conhecimentos de Estruturas das Línguas Moçambicanas, Língua de Sinais de Moçambique, Literatura Oral em Línguas Moçambicanas em diversas áreas (fonética, fonológica, morfológica, lexicológica, semântica, sintáctica, léxico-sintático, morfossintática), englobando o conhecimento cultural da comunidade linguística, têm o desafio de atender a diversidade cultural e 
linguística que caracteriza o país, pois, acredita-se que estes estarão preparados e capazes de comunicar na língua de ensino (Português e LB), incluindo o uso do sistema de grafia Braille.

Assim sendo, formação de professores de língua portuguesa no contexto de multiculturalismo, plurilinguístico e diversidade requer que se mantenham os princípios identitários, éticos, académicos, pedagógico-didácticos, técnicos-profissionais, recorrendo no acto do PEA às realidades dos grupos étnicos, sociais e linguísticos para melhor interacção entre o professor e o aluno. O conhecimento da língua local é fundamental para uma aprendizagem significativa porque reconhecer uma língua significa muito mais do que o simples uso dessa língua, visto que a língua simboliza respeito pelas pessoas que a falam, pela sua cultura e inclusão integral na sociedade, e constitui um património da humanidade, uma prática social que permitem a interacção com os outros, possuindo cada língua diferentes estratégias para representar e compreender o Mundo (SÁ \& ANDRADE, 2008).

Obviamente que também as línguas bantu permitem a interacção entre nós, utilizando vários estratégias para a representação do mundo, por exemplo em Cimakonde podemos encontrar 3 classes prefixais para o mesmo animal: nguluve (1 porco), dinguluve (porcos não definido na mente - referente), vanguluve (porcos definido na mente - expressão referencial que resulta da especificidade, e também com a carga semântica pejorativa porque o morfema va- é da classe 2 reservado para os seres humanos) $)^{6}$.

Na verdade, além do conhecimento linguístico abarcara complexidade de diversas áreas: fonética, fonológica, morfológica, lexicológica, semântica, sintáctica, léxico-sintático, morfossintática, engloba o conhecimento cultural da comunidade linguística. De facto, o léxico de uma língua é utilizado pelos seus utentes em determinados momentos e espaços específicos, guardando a sua interpretação semântica. Alguns aspectos linguísticos não se operam da mesma forma entre o Português e as línguas bantu, a título exemplificativo é o caso da ausência das formas de tratamento em algumas línguas bantu, ocorrência dos morfemas de pessoa e de número na posição pré-radical e em Português pós-radical.

Por estas razões, ensinar e educar na

diversidade exige principalmente tolerância, exige respeito ao outro, condição necessária à democracia (...) [e] o respeito pelos direitos do outro, a solidariedade, a tolerância com as diferenças devem fazer parte da filosofia educativa deste nosso tempo, ligando-se harmonicamente à dignidade da pessoa humana" (SANTOS, 2005, p. 39).

O que é mais importante hoje e no nosso contexto, é a promoção de formações continuadas em Didáctica de Pedagogia e Desenvolvimento Curricular, porque ensinar e educar na diversidade, segundo Santos (2005), exige principalmente

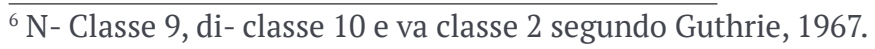


tolerância, respeito ao outro, respeito pelos direitos do outro, a solidariedade e a tolerância com as diferenças devem fazer parte da filosofia educativa actualmente, ligando-se com a dignidade da pessoa humana. $\mathrm{O}$ que quer dizer que, os PLP, leccionando com o conhecimento/formação da Didáctica da Diversidade ou plurilinguismo, facilitaria o PEA dos aspectos fonético-fonológicos, morfológicos, sintácticos e semânticos-pragmáticos e lexicais, coadjuvando o novo paradigma da educação formal - introdução das LB e o ensino da norma do Português Padrão em Moçambique.

Porém, formação inicial, além de ter fornecido a teoria educativa e da docência, a interacção entre a teoria e a prática pedagógica, domínio de uma série de saberes, capacidades e habilidades especializadas da arte do ensino e práticas que torna o professor competente no exercício da docência em Língua Portuguesa, é uma premissa para que os professores moçambicanos aprendam e se formem em outras línguas locais e estrangeiras. Com o conhecimento de outras línguas, é claro que o professor como actor social e utente de línguas realiza o PEA na base das práticas sociais e linguísticas, ou melhor, vivendo na diversidade e preparado para trabalhar na diversidade cultural, lida sempre com as culturas e as línguas, daí o reconhecimento das línguas como um conjunto de símbolos e constituem os elementos do sistema de representação do mundo e, igualmente, são sistemas de comunicação. Mas a língua que ensina é uma parte, simbolismo e reflexo da cultura diversificada em que a comunidade do educador e do aluno tem a visão do mundo pelo sistema de representação e interagem pelo sistema de comunicação.

\section{Construção da identidade do professor da Língua Portuguesa na diversidade}

O processo de construção de identidades profissional é marcada pelas experiencias vividas ao nível social, na vida escolar, na formação e no exercício profissional ou entre outras formas. A identidade dos professores é construída em dois processos distintos: identidade em formação (trajectória escolar) e identidade em exercício (trajectória profissional) percurso de construção de identidade profissional que vai se efectivando através de uma dupla transacção, nomeadamente: biográfica - de identidade para si (transacção interna ao indivíduo) e relacional - de identidade para o outro (transacção externa entre o indivíduo e as instituições) (DUBAR, 1997, 2003).

A (re)construção da identidade profissional do PLP num contexto do multilinguismo/multiculturalismo e da diversidade é feita na base de constantes desafios, passando pela valorização da língua de ensino e da profissão docente e a formação continuada e inicial no quadro do contexto local. A nosso ver também a mobilidade de professores, a inovação, a criatividade e as práticas pedgogico-didácticas actualizadas e inovadas são atitudes que reconstroem a identidade profissional do PLP. Por conseguinte, com uma formação e capacitações que inclui a matéria 
da diversidade, multiculturalismo, multilinguismo e biodiversidade se terá um professor que pauta pelos princípios da diversidade e trabalhando no quadro desta quatros categorias. Mas, o importante é o professor assumir que vive no contexto da diversidade cultural e da educação globalizada e realizar as suas práticas educativas no espírito da diversidade linguística e multicultural.

De forma similar, o professor deve realizar as suas práticas educativas no espírito das possibilidades - ambientais, sociais, culturais, económicas, epistemológicas e valorizar todas as línguas como espaços possíveis de comunicação, não podendo determinar à partida as línguas a ensinar ou a aprender, importando educar para a interacção com o outro que utiliza outra(s) língua(s) e educar para as possibilidades da intercompreensão, de entendimento entre sujeitos que pertencem a universos linguístico-comunicativos diferentes (ANDRADE; SÁ, s/d, p. 92).

Entendemos nós que, ao longo da trajectória escolar, o aluno familiariza-se com vários campos de saber e diversas pessoas com personalidades diferentes. Aqui vai desenvolver o gosto pelas áreas científicas e consequentemente a vocação ou inclinação pela área profissional ligada ao campo do domínio científico, como também focar mais atenção nas áreas científicas que têm a ver com o curso que o aluno sonha ou pretende fazer no futuro. Se pensa ser professor vai construindo referências nos seus professores, tirando deles o que marca e que vai ser como modelo ao longo da vida. É neste período que se decide em cursar a profissão de professor, neste caso, com o domínio da Língua Portuguesa, com gosto pelas línguas e pela docência e gosto em trabalhar com pessoas.

Já na formação profissional de docência, o formando socializa-se com as teorias da educação, ou seja, teorias e práticas de ensino, pedagógico-didácticas ou metodológicas e disciplinas de áreas específicas ou nucleares de formação, bem como as disciplinas das áreas complementares. Nesta fase aprende-se vários aspectos da docência, há socialização com as escolas, pratica-se o acto de leccionação no processo de estágio e simulação de leccionação nas aulas. Socializa-se com os colegas formandos que serão nos anos posteriores colegas na vida profissional, mas também aqui no processo de formação, o formando vai construindo suas referências com os formadores.

Ao longo da trajectória profissional, o professor (re)constrói a identidade profissional docente através do retrato da vida pessoal, das experiências e convivências vividas ao longo da sua vida no meio académico, social e profissional. É esta biografia que co-ocorre na sua relação interna profissionalmente ou a transacção da identidade individual, por um lado, e por outro lado, o professor (re) constrói a identidade profissional docente na base das relações externas com as outras pessoas (os professores colegas) e das relações que tem com as instituições educativas. Esta transacção relacional assente na identidade do EU para com o OUTRO ou do OUTRO para o EU, isto é, relação entre os actores da escola.

Esta segunda trajectória de construção da identidade profissional docente se desenvolve também em consonância pela estrutura do ciclo de vida profissional 
de professores de Huberman (1995). Na estrutura do ciclo de vida profissional de professores, Huberman identifica cinco fases da carreira profissional:

(i) Entrada: o início na carreira correspondendo de 1 a 3 anos em que neste período o professor faz descobertas e sobrevivência da profissão;

(ii) Estabilização: ocorre entre os 4 a 6 anos e é caracterizada pela libertação e afirmação nos aspectos pedagógicos e um sentimento de competência pedagógica crescente;

(iii) Diversificação: ocorre entre os 7 a 25 anos de carreira e os professores neste período apresentam uma motivação e empenho, sendo também dinâmicos e com um questionamento mais elevado;

(iv) Serenidade e distanciamento afectivo: ocorre entre os 25 a 35 anos em que o professor apresenta a tendência de uma concentração, conservador e procurando situações de estabilidade profissional;

(v) Desinvestimento: ocorre entre os 35 a 40 anos e neste período os professores desinvestem progressivamente, transmitem o seu testemunho e experiências aos jovens, preparando a sua retirada na vida profissional e ficando conselheiros em alguns casos.

Mas dependendo de pessoa para pessoa, há diversas maneiras de se viver a carreira do professorado e cada um define o seu perfil e os projectos de vida durante e depois do exercício da profissão. E as fases supra-propostas por Huberman são sistematizadas no quadro 1.

Quadro 1: Ciclo da carreira profissional de professor

\begin{tabular}{|c|c|c|c|}
\hline Ord. & Anos de Carreira & Fases & Caracterização \\
\hline $1^{\mathrm{o}}$ & $\begin{array}{l}\text { 1-3 anos } \\
\text { de experiência }\end{array}$ & Entrada & $\begin{array}{l}\text { Tacteamento } \\
\text { e descoberta }\end{array}$ \\
\hline $2^{o}$ & $\begin{array}{c}\text { 4-6 anos } \\
\text { de experiência }\end{array}$ & Estabilização & $\begin{array}{l}\text { Consolidação dum } \\
\text { repertório pedagógico }\end{array}$ \\
\hline $3^{0}$ & $\begin{array}{c}\text { 7-25 anos } \\
\text { de experiência }\end{array}$ & Diversificação & $\begin{array}{c}\text { Activismo } \\
\text { e questionamento }\end{array}$ \\
\hline $4^{\circ}$ & $\begin{array}{c}\text { 25-35 anos } \\
\text { de experiência }\end{array}$ & $\begin{array}{c}\text { Serenidade e } \\
\text { distanciamento } \\
\text { afectivo }\end{array}$ & $\begin{array}{l}\text { Conservadorismo } \\
\text { e limitações }\end{array}$ \\
\hline $5^{\circ}$ & $\begin{array}{c}\text { 35-40 anos } \\
\text { de experiência }\end{array}$ & Desinvestimento & Sereno ou amargo \\
\hline
\end{tabular}

Fonte: (HUBERMAN, 1995, p. 47) (adaptado) 
Num contexto da diversidade e com as influências dos organismos internacionais constrói-se a identidade profissional, primeiro, pelo reconhecimento da diversidade e ajustamento do professor à realidade do contexto, aglutinando a multiplicidades de aspectos da diversidade cultural, linguístico e da biodiversidade ao serviço da docência e do local onde o professor possa trabalhar. O professor tem que actuar no quadro das realidades dos organismos nacionais e internacionais.

O professor socializa-se, formando a sua identidade, num processo de tolerância linguística e no contexto de compreensão do EU, do OUTRO e do MUNDO sem fronteiras naturais, com isto quer dizer que compreende as mutações que o rodeia e a realidade que o circunda, em que educa "para o desenvolvimento sustentável e diversidade linguística e cultural (...) [em que estão incluída três entradas] uma entrada pelos sujeitos; uma entrada pelas línguas e culturas; uma entrada pelos ambientes naturais e sociais em que os sujeitos se movimentam" (ANDRADE; SÁ, s/d, p. 95).

Para a compreensão do EU, do OUTRO e do MUNDO, de acordo com os entrevistados, pode-se (re)construir a identidade profissional docente também através de acções estratégicas, como:

a) massificação e expansão do ensino das línguas locais (bantu) nas escolas públicas e privadas. A massificação e expansão do ensino das LB poderá consciencializar os professores em dar primazia ao ensino destas línguas e munir-se de recursos matérias;

b) promoção de capacitações em matéria do bilinguismo e ensino bilingue que permitiria ao professor de língua dar o seu contributo que favorece a auto-formação;

c) Os definidores de PPE devem fazer entender aos professores para melhor implementação dos currículos, pois, com professores que não conheçam o espírito da política linguística, da política educativa e das directrizes do sistema educativo, caíra-se no descrédito, insucesso e consequentemente pode se perder "de vista que a educação para outras línguas se joga na proximidade/afastamento linguístico-comunicativo” (op.cit, p. 92);

d) Formação dos professores em uma ou duas línguas locais, podendo ser com indivíduos formados em Linguística Bantu e os locutores, jornalistas e repórter, que trabalham nas rádios, televisões e nos jornais, os pastores ou crentes e pessoas que têm o domínio e proficiência das nossas LB.

No entanto, subjaza três tipos de construção de identidade profissional docente: involuntária, voluntária e colectiva crítica. A primeira, é adquirida em contexto 
familiar e em situações profissionais, em que o professor pelas formas de estar e ser de alguns membros familiares docentes, vai, informal e inconscientemente, fazendo aquisições do processo educativo que resultam do conjunto das características voltadas ao sistema educativo destes actores familiares e/ou dos membros co-vizinhos. É uma aquisição de condutas que actuam eficazmente nos processos educativos pelos comportamentos dos outros colegas professores e pela filosofia de estar na escola (comportamento da escola e fora dela). É uma construção externa que provém a partir das acções do OUTRO, influenciando deste modo o EU. A segunda, é de construção interna, a partir do EU, isto é, é intrinsecamente inerente ao sujeito que procura uma identidade própria de estar nos processos educativos. O sujeito professor cria sua identidade própria que o distingue dos outros professores, podendo ser pelas suas práticas pedagógicas novas, pela opção de uma forma de trabalhar diferente dos outros, conduta própria, aprendizagem e auto-formação constante, etc. A terceira, reside pela reflexão crítica e reconstrução identitária profissional a partir das novas situações ou paradigmas da educação, em que os professores procuram, colectivamente, reflectir sobre a nova forma de estar e conduta a partir das novas situações do processo educativo, analisando a sua profissão, sua identidade profissional e sua situação actual, novos caminhos e perspectivas, para actuarem em conformidade no campo educacional.

Mas, para os professores do "futuro próximo, deverão aprender a caminhar e a construir a sua identidade” profissional (LESSARD; TARDIF, 2014, p. 277) e a personalidade destes que resulta do processo interactivo com vários actores, em especial o aluno, será avaliado na base das suas praxis e da qualidade de ensino por eles produzidos, com forte controle de todos segmentos sociais. Estes devem privilegiar também a pedagogia para autonomia na "abordagem pedagógica centrada no aluno e comprometida com o desenvolvimento da sua autonomia, constitui, ainda hoje, um ideal pedagógico, um desafio para os profissionais da educação" (VIEIRA, 1998, p. 26).

Diante do que foi dito, pode-se acreditar que há necessidade da formação de profissionais qualificados da educação e professores com forte influência do paradigma reflexivo "schöniano" e com excelente qualificação que lhe permite realizar o processo educativo centrado no aluno, na aprendizagem e construção de conhecimentos voltada para o respeito da diversidade, especialmente às diferenças linguísticas, culturais, sociais, étnicas. Portanto, a construção da identidade do professor, hoje, é feito em contexto de lugares complexos - em casa, na escola, nos diferentes subsistemas de ensino e em outros espaços em que o professor vivencia as diversas formas identitárias, as experiências, os costumes ou hábitos, as crenças, os valores, as representações biografias dos OUTROS e do EU e dos processos educativos. E é neste quadro de situações e perspectivas que se deve formar e construir a identidade docente porque se ajustam para este mundo da diversidade cultural, linguística e globalizado. 


\title{
5 Considerações finais
}

Neste artigo reflectimos a relação entre o currículo de formação de professores primários no contexto plurilinguístico e Pedagogia da Diversidade com um olhar aos professores de língua portuguesa. Sobre o currículo de formação de professores, ressalta-nos o enquadramento do mesmo num processo de formação crítica e reflexiva e na base das teorias pós-críticas e o pós-estruturalismo do currículo, equilíbrio da GC e DC e incorporação da Pedagogia da Diversidade (SANTOS, 2005; DIAS, 2009) e Desenvolvimento Curricular, com o pendor neste caso, a questão de multilinguismo e diversidade cultural.

No nosso contexto plurilingue, os professores do ensino primário de língua portuguesa deviam ser bilingues equilibrados, tendo em conta o local da escola pois usariam o codeswitching (mudança de código para outro na comunicação) no processo de ensino e aprendizagem.

Todas as línguas devem concorrer para a formação do homem, cabendo o desenho de uma política linguística que favorece a tal intenção e formação de professores para actuar em contextos multilingues e da diversidade cultural.

\section{TRAINING OF PRIMARY EDUCATION TEACHERS IN THE CONTEXT OF CULTURAL DIVERSITY - A LOOK AT PORTUGUESE LANGUAGE TEACHERS IN MOZAMBIQUE}

\begin{abstract}
With this article, we intend to address the training of primary teachers of Portuguese language in the context of cultural diversity, with the purpose of reflecting on the curriculum for training primary teachers in Mozambique. The methodology used consisted of bibliographic and documentary research based on Curriculum Plan for the Training Course for Primary School Teachers and Adult Educators, among other documents and interviews of fourteen teachers. We emphasize the need to incorporate the Pedagogy of Diversity and Curriculum Development in the training of teachers because it is not foreseen and solid, secure and stable courses. They would prepare future teachers for critically reflect on the Basic Education curriculum and for develop students' awareness of linguistic, cultural and biodiversity diversity, in order to guide them towards an activity that is significant to them, enabling them to build their identity, human condition and citizenship at the base of post-structuralism e post-critic theories. Having a balanced bilingual teacher would be an appropriate scenario given the workplace and language policy that favors all languages in the Mozambican space in education. Without these tools, there may be difficulties for teachers because they will work in a context of cultural and linguistic diversity, and they should sometimes teach the Bantu and Portuguese languages, not enough knowledge of the Structures of the Bantu Languages, Didactics of the First Language / Maternal, Second Language Didactics, Portuguese Language, Oral Literature, the country's linguistic and cultural situation.
\end{abstract}

Keywords: Curriculum; Teacher training; Didactics of Diversity; Cultural diversity. 


\section{Referências}

ANDRADE, ANA; SÁ, Susana. Educação para o Desenvolvimento Sustentável e Diversidade Linguística: que possibilidades? Disponível em: «https://core.ac.uk/ download/pdf/61912379.pdf» Acesso em 10 de Novembro de 2018.

BARZOTTO, Valdir H.; PUH, Milan. O Perfil e a Atitude Investigativa do Profissional de Letras diante do Dado no Relatório de Estágio. In: RIOLFI, Cláudia (Org.) Professor de Português: como se forma, trabalha e entende sua prática. São Paulo: Paulistana, 2015.

BERNSTEIN, Basil. A Estruturação do Discurso Pedagógico - Classe, Códigos e Controlo. Petrópolis: Vozes, 1996.

BOURDIEU, Pierre; PASSERON, Jean Claude. A Reprodução: elementos para uma teoria do sistema educativo. 3. ed. Rio de Janeiro: Francisco Alves, 1992.

CARVALHO, Marlene Araújo de. A Formação de Professores e os Fundamentos da Ação Docente. Disponível em «http://leg.ufpi.br/subsiteFiles/ppged/arquivos/ files/eventos/evento2002/GT. 1/» Acesso em 8 de Abril de 2016.

CORTELLA, Mário Sérgio. A Escola e o Conhecimento: fundamentos epistemológicos e políticos. 7. ed. São Paulo: Cortez, 2003.

CORTESÃO, Luiza; STOER, Stephen R. "A Interface de Educação Intercultural e a Gestão de Diversidade na Sala de Aula”. In: GARCIA, Regina Leite; MOREIRA, António Flávio (Org.) Currículo na Contemporaneidade: incertezas e desafio. São Paulo: Cortez, 2003.

CORREIA, José Alberto. Formação e Trabalho: contributos para uma transformação dos modos de pensar na sua articulação. In: CANÁRIO, Rui (Org.) Formação e Situações de Trabalho. Porto: Porto, LDA, 2003..

DIAS, Hildizina. Saberes Docentes e Formação de Professores na Diversidade Cultural. Maputo: Imprensa Universitária, 2009.

DUBAR, Claude. A Socialização: construção das identidades sociais e profissionais. (Trad. de Anette P. R. Botelho e Estrela P. R. Lamas). Porto: Porto 1997.

DUBAR, Claude. Formação, Trabalho e Identidades Profissionais. In: CANÁRIO, Rui (Org.) Formação e Situações de Trabalho. Porto: Porto, 2003. pp. 43-52.

FOUCAULT, Michel. Vigiar e Punir: nascimento da prisão. (Trad. de Raquel Ramalhete). 20. ed. Petrópolis:Vozes, 2014.

GARCÍA, Carlos Marcelo. Formação de Professores: para uma mudança educativa. Porto: Porto, 1999.

GIROUX, Henry H.; McLAREN, Peter. Formação do Professor como uma Contraesfera Pública: a pedagogia radical como uma forma de política cultural. In: MOREIRA, António F. B.; TADEU DA SILVA, Tomaz (Orgs.) Currículo, Cultura e Sociedade. 3. ed. São Paulo: Cortez,1999.pp. 125-155. 
GOODSON, Ivor F. Currículo: teoria e história. (Trad. de AnttílioBrunetta). 6. ed. Petrópolis: Vozes, 2003.

GOODSON, Ivor F. As Políticas de Currículo e de Escolarização: abordagens históricas. Petrópolis: Vozes, 2008.

HUBERMAN, Michaël. O Ciclo de Vidas Profissional dos Professores. In: NÓVOA, António (Org.) Vidas de Professores. Porto: Porto, 1995. pp. 31-61.

INSTITUTO NACIONAL DE DESENVOLVIMENTO DA EDUCAÇÃO; MINISTÉRIO DA EDUCAÇÃO E DESENVOLVIMENTO HUMANO. Plano Curricular - Curso de Formação de Professores do Ensino Primário e educadores de Adultos. Maputo, Agrimag, 2019.

LESSARD, Claude; TARDIF, Maurice. As Transformações Actuais do Ensino: três cenários possíveis na evolução da profissão de professo?. In: TARDIF, Maurice ; LESSARD, Claude (Orgs.). Ofício de Professor: histórias, perspectivas e desafios internacionais. (Trad. de Lucy Magalhães). 6. ed. Petrópolis: Editora, 2014. pp. 255-277.

LOPES, Alice Casimiro; MACEDO, Elizabeth. Teorias do Currículo. São Paulo: Cortez, 2011.

McLAREN, Peter. Multiculturalismo Crítico. 3. ed. São Paulo: Cortez, 2000.

MOREIRA, Jacinta. Modelos de Formação Inicial de Professores de Ciências Naturais - um estudo a partir dos discursos sobre as práticas dos formadores. In: LEITE, Carlinda e LOPES, Amélia (Orgs.) Escola, Currículo e Formação de Identidades. Porto: Edições ASA, 2007. pp. 232-254.

NHALIVILO, Emília Afonso. Universidade e inter/diversidade: caminhos possíveis no mapa de desenvolvimento. (Aula Inaugural na Universidade Pedagógica Delegação de Montepuez, 22 de Março de 2017).

NÓVOA, António. O Passado e o Presente dos Professores. In: NÓVOA, António (Org.) Profissão Professor. Porto: Porto 1991.

PACHECO, José Augusto. Territotializar o Currículo Através de Projectos Integra. In: PACHECO, José Augusto (Org.) Políticas de Integração Curriculares. Porto: Porto, 2000.

PACHECO, José Augusto. Currículo: teoria e praxis. 3. ed. Porto: Porto, 2001. PACHECO, José Augusto. Estudos Curriculares: para compreensão crítica da educação. Porto: Porto, 2005.

PINAR, William. Autobiography, Politics and Sexuality. New York: Peter Lang, 1994.

POURTOIS, Jean-Pierre; DESMET, Huguette. A Educação Pós-moderna. São Paulo, Edições Loyola, 1999.

ROLDÃO, Maria do Céu. Os Professores e a Gestão do Currículo: perspectivas e práticas em análise. Porto: Porto, 1999. 
SÁ, Susana \& ANDRADE, Ana Isabel. "Aprender a Respeitar o Outro e o Planeta”: potencialidades da educação para o desenvolvimento sustentável nos primeiros anos de escolaridade. In: Revista Iberoamericana de Ciência, Tecnologia y Sociedad-CTS, Vol. 4, Nr. 11, 2008. pp. 115-138. Disponível em: «http://www. rdalyc.org/articulo.ao?id\#92441108», Acesso em 9 de Abril de 2019.

SANTOMÉ, Jurjo Torres. Currículo Escolar e Justiça Social: o cavalo de Tróia da Educação. (Trad. de Alexandre Salvaterra). Porto Alegre: Penso, 2013.

SCHÖN, Donald A. Formar Professores como Profissionais Reflexivos. In:

NÓVOA, António. (Org.) Os Professores e a sua Formação. 2. ed. Lisboa: Instituto de Inovação Educacional, 1995.

SANTOS, $M^{a}$. Sirley dos. Pedagogia da Diversidade. São Paulo: Memnon Edições Científicas Ltda, 2005.

TADEU DA SILVA, Tomaz. Documentos de Identidade: uma introdução às teorias do currículo. 3. ed. Belo Horizonte: Autêntica Editora, 2017a.

VIEIRA, Flávia. Autonomia na Aprendizagem da Língua Estrangeira: uma intervenção pedagógica em contexto escolar. Braga, UniMinho - Instituto de Educação e Psicologia, 1998.

Recebido em 18 de outubro/2020 Aprovado em 22 de dezembro/2020 